\title{
Return to Work in Patients with Acute Coronary Syndrome
}

\author{
Deddy Tedjasukmana
}

Department of Physical Medicine and Rehabilitation, Cipto Mangunkusumo National General Hospital, University of Indonesia

\begin{abstract}
Acute coronary syndrome (ACS) is a medical term used to describe problems that occur when there isn't enough blood flow to the heart, can lead to chronic heart disease (CHD). In Indonesia, 17.3 million deaths were caused by CHD in 2008, it can be increased to 23.3 million deaths in 2030. A recent study states that ACS was increased among worker age. Therefore, the ability to return to work is important, because it can impact on the economic status of patients and their families, the patients' quality of life, and also psychosocial factors.

Patients who are hospitalized due to coronary heart disease need to have a cardiac rehabilitation program that is divided into three phases. The patients are given a program that suits with their individual risk stratification to achieve their vocational needs. The ability to work, work risk, work capacity, and work tolerance needs to evaluated by exercise test.

After a comprehensive evaluation of coronary patients, it is important to determine suitability for work. In general, post-Percutaneous Coronary Intervention (PCI) ACS can return to previous jobs with some adjustments if needed. Energy expenditure monitoring during working can be measured by indirect and direct measurements.
\end{abstract}

Keywords: Acute Coronary Syndrome, Cardiac Rehabilitation, Return to Work, Coronary Heart Disease.

\section{Correspondence Detail:}

\section{Deddy Tedjasukmana}

Email: deddytedjasukmana@yahoo.co.id

Department of Physical Medicine and Rehabilitation,

Medical Faculty of University of Indonesia, Dr. Cipto Mangunkusumo National General Hospital Address: Jl. Pangeran Diponegoro No.71, Senen, Jakarta Pusat, Indonesia, 10430

\section{INTRODUCTION}

Nearly $45 \%$ of patients with acute coronary syndrome (ACS) are less than 60 years old or still in working age. More than $40 \%$ of the population has worked 15 years or more at the same job and $37 \%$ of the population requires the high level of expertise in work. Return to work after ACS is an important indicator in the recovery phase. Return to work has impacts 
on the economic status of patients and their families, and as a reflects of good health and well-being. ${ }^{1,2}$

Dreyer RP et al has found that, Acute Myocardial Infarction (AMI) is a life-changing event that is often accompanied by a complex of emotional reactions, including fear, anxiety, depression, that can be a barrier to recovery of the functioning, including the ability to work. Cardiac rehabilitation on return to work is essential for patients' function recovery, ${ }^{3}$ so return to work is a primary rehabilitation goal on post-myocardial infarction (MI), post PCI, and coronary artery bypass graft $(\mathrm{CABG}){ }^{2}$

Definition of the ACS by American College of Cardiology Foundation (ACCF) / American Heart Association (AHA) in 2014 is a spectrum of conditions compatible with acute myocardial ischemia and/or infarction that are usually due to an abrupt reduction in coronary blood flow, can lead to chronic heart disease (CHD). ${ }^{4}$

Epidemiology of the ACS by AHA in 2016 was 15.5 million people aged $\geq 20$ years who had coronary heart disease (CHD) in the United States, and the prevalence increases with age in both men and women. ${ }^{5}$ While, in Denmark, the hospitalization rate for acute myocardial infarct increase from 2,560 to 3,091/mil. Population. However, early mortality decreased from $26 \%$ in 1994 to $17.5 \%$ in $2002 .{ }^{6}$

In Indonesia, 17.3 million deaths were caused by CHD in 2008, and predicted increasing to 23.3 million deaths in 2030. The prevalence of CHD increasing by the age, on $45-54$ years is $0.7 \%$, on 55-64 years is $1.3 \%$, and on $65-74$ years is
$2 \%$, based on doctor's diagnosed. The highest prevalence of CHD in Indonesia was at Central Sulawesi $(0.8 \%)$ followed by North Sulawesi, DKI Jakarta, and Aceh ( 0.7\%). ${ }^{7}$

The pathophysiology of ACS is start by atheroma plaque of a ruptured coronary artery. ${ }^{8}$ This is related to changes in plaque composition and thinning of the fibrous hood covering the plaque, followed by platelet aggregation and activation of the coagulation pathway. Platelet-rich thrombus (white thrombus) is formed, then clog the coronary arteries, both totally and partially; or become micro-emboli which clogs more distal coronary arteries. In addition, there is the release of vasoactive substances, causing vasoconstriction and disturbs coronary blood flow. Reduced coronary blood flow causes myocardial ischemia. Oxygen supply that stops for approximately 20 minutes causes the myocardium to become necrosis (MI). ${ }^{4,8}$

Diagnosis of ACS is based on history, physical examination, electrocardiogram (ECG), and examination of cardiac enzymes. ACS can be divided into unstable angina pectoris (UAP), non-ST-segment elevation myocardial infarction (NSTEMI), and elevation ST-segment myocardial infarction (STEMI). Diagnosis of unstable angina pectoris is established if one or more of the following symptoms are found, (1) chest pain at rest for more than 20 minutes, (2) new onset chest pain ( $<2$ months before), and (3) crescendo pattern (increasing intensity, duration, and frequency), and normal value of cardiac enzyme (Troponin T). There is an increase in cardiac enzymes without elevation in the ST segment in NSTEMI, however the STEMI is an elevation in the ST segment. ${ }^{4,8}$ 
Management of the ACS determined by the pat ophysiological of NSTEMI/UAP and STEMI. There is a total occlusion in STEMI, thus pharmacological reperfusion therapy and catheterization are the main choices to restore normal blood flow. While, in NSTEMI/UAP, the goal of antithrombotic therapy is to prevent new thrombus formation and help endogenous fibrinolysis to dissolve thrombus and reduce the degree of coronary stenosis. Definitive management of NSTEMI are anticoagulants, platelet inhibitors, and consideration for immediate invasive actions.

\section{Cardiac Rehabilitation in Acute Coronary Syndrome (ACS)}

Based on the Guidelines for Cardiac Rehabilitation and Secondary Prevention Programs, patients who are hospitalized due to coronary heart disease need to have a Rehabilitation Program as followed: Initial examination and early mobilization; Identification and information about risk factors and self-care; $\mathrm{C}$ ontinuing cardiac transitional rehabilitation program, outpatient phase and maintenance phase. ${ }^{9}$

Important examinations during the cardiac rehabilitation program are cardiovascular and respiratory system physical examination, followed by resistance training test, electrocardiography, and echocardiography. Resistance training tests are conducted to measure cardiorespiratory function, and the relationship of risk stratification, return to work, exercise prescribing, and management of training programs. The simple resistance training tests are a 6-minute walk tesrt, treadmill, or ergocycle test. The Echocardiography test is to measure the patient's ejection fraction. ${ }^{10}$

The Phase of Cardiac Rehabilitation Cardiac rehabilitation in ACS divided into three phases, phase I (inpatient) for 5 days, phase II (outpatient) for 4-8 weeks and phase III (maintenance) for 3-6 months.

\section{Phase I (Inpatient)}

In this phase, the rehabilitation given are education, early mobilization, and training according to the patient's condition. The activity must begin with a dynamic exercise with low intensity (1-2 METs), with the target is independent activity of daily life (ADL) and target of functional activities 3-4 METs (Metabolic equivalent). Cardiac rehabilitation program at the ICCU is carried out for 5 days after the patient is stabilized, especially in patients without complications. Progressive activity during five days of care can be seen in table $1 .^{10}$

Before going home from treatment, a six-minute walking test is performed to provide training response data that is useful for activity guidelines at home and to continue the outpatient phase program. ${ }^{10}$ 
Table 1. Progressive activity during five days of care

\begin{tabular}{|c|c|c|}
\hline & Level of MET & Activity \\
\hline First day & $1-2$ & $\begin{array}{ll}\text { - } & \text { Bed rest until stable } \\
\text { - } & \text { Sit on the chair beside bed / Out of bed (OOB) } \\
\text { - } & \text { Defecate beside bed }\end{array}$ \\
\hline Second day & $2-3$ & $\begin{array}{l}\text { - } \text { Routine activity in ICCU including self-care } \\
\text { - } \text { Sit while doing the light movement } \\
\text { - Walking inside the room }\end{array}$ \\
\hline Third day & $2-3$ & $\begin{array}{l}\text { - Sit on the chair beside the bed } \\
\text { - Stand up while doing the light movement } \\
\text { - Walk for 5-10 minutes in a corridor, 2-3 times a day (with } \\
\text { supervision) }\end{array}$ \\
\hline Fourth day & $3-4$ & $\begin{array}{l}\text { - } \quad \text { Take a shower, sitting } \\
\text { - Stand up while doing the light movement } \\
\text { - } \quad \text { Walk for 5-10 minutes in a corridor, 3-4 times a day } \\
\text { - } \quad \text { Climb up and down stairs (with supervision) }\end{array}$ \\
\hline Fifth day & $3-4$ & $\begin{array}{ll}\text { - } & \text { Routine activity } \\
\text { - } & \text { Climb up and down } 1 \text { floor } \\
\text { - } & \text { Walking exercise in treadmill }\end{array}$ \\
\hline
\end{tabular}

Source: AACVPR. Guidelines for Cardiac Rehabilitation and Secondary Prevention Programs. 5th edition. Human Kinetics, 2013; Best Practice Guidelines for Cardiac Rehabilitation and Secondary Prevention. Heart Research Centre. Department of Human Services Victoria;1999.

\section{Phase II (Outpatient)}

Patients have examination on pulmonary and neuromusculoskeletal system (especially the upper and lower extremities), 12-leads electrocardiogram at rest, and risk profile for CHD, before and after the program. This phase begins immediately after discharge from the hospital, generally takes 4 to 8 weeks to achieve an optimal functional reach of approximately 6 METs of activity. ${ }^{10}$

After finish this phase, patients got a treadmill training test to evaluate the result of exercise, and to find out whether the patient can continue to phase III. Whenever the aerobic capacity reach 6-8 METs, the patients continued to phase III of cardiac rehabilitation program. ${ }^{10}$

\section{Phase III (Maintenance)}

This phase is in the communities, that supervised by physical medicine and rehabilitation specialists. The community program is devoted to low-risk patients, clinically stable (no angina, arrhythmias during training), able to recognize the symptoms of ACS, and able to adjust the intensity of the exercise independently. This phase lasts for 3-6 months, supervised minimally, and at the end of this phase a treadmill test is carried out to enter 
the lifelong phase or for life. The target is the functional activity more than 8 METs. ${ }^{10}$

The goal of the cardiac rehabilitation program in ACS is to increase aerobic capacity, establish the collateral system on coronary artery, and followed by psychological dan physical improvement, through the exercise tailored individually. Evaluation of risk stratification before the program is necessary to determine the intensity of exercise. Risk stratification for clinical practice is an indicator that can help determine the appropriate level of supervision for each individual (Table 2) . ${ }^{9}$

Table 2. Risk Stratification

\begin{tabular}{|c|c|}
\hline Risk Grade & Characteristics \\
\hline Low Risk & $\begin{array}{l}\text { - Ejection Fraction resting }>50 \% \\
\text { - There are no ventricular dysrhythmias at rest or with exercise } \\
\text { - There is no complication from myocardial infarction or revascularization procedure } \\
\text { - There is no heart failure or symptoms and signs of post - ACS ischemia or post } \\
\text { procedure } \\
\text { - Normal hemodynamic and ECG responses during the exercise test } \\
\text { - Functional capacity }>7 \text { METs } \\
\text { - No clinically depressed }\end{array}$ \\
\hline Moderate Risk & $\begin{array}{l}\text { - Ejection Fraction resting } 40-50 \% \\
\text { - There is angina or other significant symptoms (for example: dizziness, shortness of } \\
\text { breath, feeling of drifting), which occurs during high activity (60-75\% maximum } \\
\text { functional capacity) } \\
\text { - Mild-moderate silent ischemia during exercise test or recovery (ST depressed }<2 \\
\text { mm of baseline) }\end{array}$ \\
\hline
\end{tabular}

High Risk

- Ejection Fraction resting $<40 \%$

- History of cardiac arrest or sudden death

- Complex dysrhythmias during resting or exercise test

- Myocardial infarction or revascularization procedure with difficulties (cardiogenic shock, heart failure, or symptoms and signs of post-ACS ischemia or post procedure)

- There is an abnormal hemodynamic during exercise test (for example: chronotropic incompetent or persistent systolic blood pressure or decreases with increasing load) or during recovery (hypotension after heavy training)

- Significant silent ischemia (ST depression $>2 \mathrm{~mm}$ from the baseline) during the exercise test or recovery

- There are arrhythmias or other significant symptoms (shortness of breath, a feeling of drifting, dizziness in mild activity or less than 5 METs or during recovery

- Functional capacity $<5$ METs

- Clinically depressed

Source: American Association of Cardiovascular and Pulmonary Rehabilitation. Guidelines for Cardiac Rehabilitation and Secondary Prevention Programs. Human Kinetics; 2013. 
The prescribing component of aerobic exercise for patients with cardiorespiratory disease based on The American College of Sport Medicine (ACSM) can be seen in table 3. ${ }^{11}$

Table 3. Prescribing component of aerobic exercise for patients with cardiovascular disease.

\begin{tabular}{lll}
\hline \multicolumn{1}{c}{ Component } & \\
\hline Intensity & - & Recommendation \\
& - & Generally $12-16$ from $6-20$ Borg scale as an objective measurement of heart rate \\
\hline Duration & - & $20-60$ minutes \\
& The significant functional capacity increase can be achieved if doing exercise with a \\
& longer duration
\end{tabular}

Source: Pescatello LS, American College of Sports Medicine. ACSM's guidelines for exercise testing and prescription. Philadelphia: Wolters Kluwer/Lippincott Williams \& Wilkins Health; 2014.

Training Effect in Post Acute Coronary Syndrome There are several benefits that can be gained by giving physical training to patients with ACS. Physical exercise can increase $\mathrm{VO}_{2}$ max in healthy patients by increasing maximal stroke volume and maximal $\mathrm{AV} \mathrm{O}_{2}$ difference. The increase of $\mathrm{VO}_{2}$ max will be greater as the duration and intensity of the exercise increase. The average increase in $\mathrm{VO}_{2}$ max in patients with coronary heart disease varies between $11-56 \%$. The increase in stroke volume can lower heart rate, that lower oxygen requirements, lower blood flow, and decreases the incidence of angina. ${ }^{12}$

Cardiac rehabilitation also significantly reduces mortality of heart disease. The previous study showed that participation in post PCI cardiac rehabilitation program significantly reduced the mortality rate by $47 \% .^{13}$ Another study shows that cardiac rehabilitation programs significantly reduce recurrent incidence in the first 15 months such as MI, revascularization, stenosis, angina and mortality in patients undergoing cardiac rehabilitation programs than those who don't .${ }^{14}$ Cardiac rehabilitation also increases exercise tolerance, reduces symptoms of heart disease, lipid levels, frequency of smoking, stress levels and increases adherence to treatment and the patient's psychosocial life. ${ }^{2,9}$

Return to Work In Acute Coronary Syndrome (ACS)

The role of cardiac rehabilitation is very big in predicting the return to work in patients with cardiovascular disease, especially in ACS. Education, counseling and behavioral interventions are the centers in vocational rehabilitation. ${ }^{8}$ Some studies in developed 
countries have rates of return to work on average after myocardial infarction of $63-94 \%$ in the United States, $58-80 \%$ in Sweden, $85-87 \%$ in Belgium and $90 \%$ in Denmark. ${ }^{10}$ There is no data on return to work prevalence in Indonesia.

The previous study showed most patients could return to work in two to three months after myocardial infarct (MI) but recent studies have shown a shorter period of approximately 4 weeks. Patients with asymptomatic cardiovascular disease without complication could return to work in 4 weeks post-MI, 4-8 weeks for post CABG, and 1 week for post PCI. ${ }^{10}$

\section{Factors that Affect Return to Work}

Factors that affect return to work after ACS can be divided into 3 groups: ${ }^{2,15,16}$

Medical and Sociodemographic Factor: include age, gender, education, history of previous disease, the severity of disease, complications from ACS such as arrhythmias, poor left ventricular ejection fraction, rehospitalization and low exercise capacity. Age plays the most important role compared to medical factors which are generally less relevant.

Psychosocial factor: Depression is a negative predictor to return to work in ACS; Patient's perception is patient's assessment of their ability to work, work capacity and decisions about returning to work, positive perception is needed to return to work; Patients' motivation and expectation are the desire and motivation to reachieve the work targets.

Occupation and Work Factor: Economic and employment factors (health insurance and financial incentives, employment rates, physical and mental workload demands) have to provide the possible risk of relapse related to cardiac events; Socioeconomic status is the difficulty of returning to work relates to low socioeconomic status, especially in blue-collar workers that need high physical capacity to return to work; Work environment is a workload demands of previous work environment, that can be the negative predictors of returning to work or causing "delayed return to work" after ACS; Social support at work is supported from co-workers as an important factor.

The cardiac rehabilitation program affects the functional capacity and improves cardiorespiratory symptoms that have a positive relation with the ability to work. ${ }^{4,89}$ Ben-Ari found that return to work can be achieved approximately at 18 months which is higher for them who are taking cardiac rehabilitation programs compared to other patients (84\% and 64\%). ${ }^{17}$

\section{Monitoring of Energy Expenditure}

During working, the energy expenditure can be monitored by Indirect and Direct measurements; Indirect measurements by redicting the response of workers to the base of exercise tests or previous job performance such as: Activity while working (the calories were depend on the type, speed, rest, how many cycles, patterns of work, environment and expertise, time spent sitting, standing, walking, climbing stairs, are there activities that require bending, arms or body movements and transportation required, by simple methods; time recording by an observer/ the patient, accelerometry and pedometry); Job description (Oxygen uptake or calories can be calculated from job descriptions which are arranged into standard tables. Beside, energy requirements can be estimated by reducing the energy used for 
daily activities in food intake) ${ }^{2}$; Physiological responses in the workplace (physical activity, oxygen uptake, mental condition, intellectual and environmental factors such as noise and temperature. $^{2}$ The average level of oxygen consumption during 8 hours of work was $33 \%$ of VO2Max obtained from the results of the training test. ${ }^{18,19}$ )

Direct measurements to workers' responses, included; Cardiovascular response (heart rate, blood pressure, ECG changes), Respiratory response (volume of ventilation per minute and velocity of ventilation, assessment of ventilation per minute increases linearly with oxygen uptake), the regulatory response to temperature (body temperature and amount of sweat, especially in jobs with heat exposure such as fire extinguisher and iron smelting), metabolic response (lactic acid in heavy work physical loads such as fire engines, and catecholamines in jobs with high mental and emotional stress)

\section{Return to Work Evaluation}

Return to work requires an evaluation of the abilities and limitations of each individual and adjusting to the job requirements that can be expected with normal people according to their age. ${ }^{2}$ In evaluating the ability to work, there are 3 things needed to be considered ${ }^{17}$; Work risk (Under certain conditions, work restrictions need to be made regarding the patient's medical condition); Work capacity (working capacity can be increased and measured as regular exercise, then evaluate the signs and symptoms regarding his medical condition); Work tolerance (Psychophysiological state of a person to performs work activities comfortably, can be influenced by emotions, a history of disease or discomfort; chest pain, feeling tight, fatigue during work activities, and also economic factors).

The identification of the work type and functional capacity are the essential aspect in return to work program on ACS patients. The result of risk stratification can be a guidance for medical management and vocational rehabilitation. ${ }^{13,18}$ Physiology process in working activity is the most important thing to predict the ability to work for 8 hours in a day. ${ }^{13}$

Measurement of working capacity or physiology test measured by the incremental exercise test (graded exercise testing). Stress training test is physiological method for measuring physical capacity. The intensity of the training test which can reach $80-85 \%$ of the maximum heart rate, that is greater than the cardiorespiratory capacity for 8 hours of work. ${ }^{3,18}$

Another important measurement is the ejection fraction of systolic function, that is the standard of angiographic left ventriculography. The normal ejection fraction is more than $50 \%$, mild dysfunction is $40-50 \%$, moderate dysfunction is $30-40 \%$ and severe dysfunction is less than 30 $\% .^{3}$

Criteria for return to work algorithm in ACS can be seen in figure $1{ }^{2}$ 


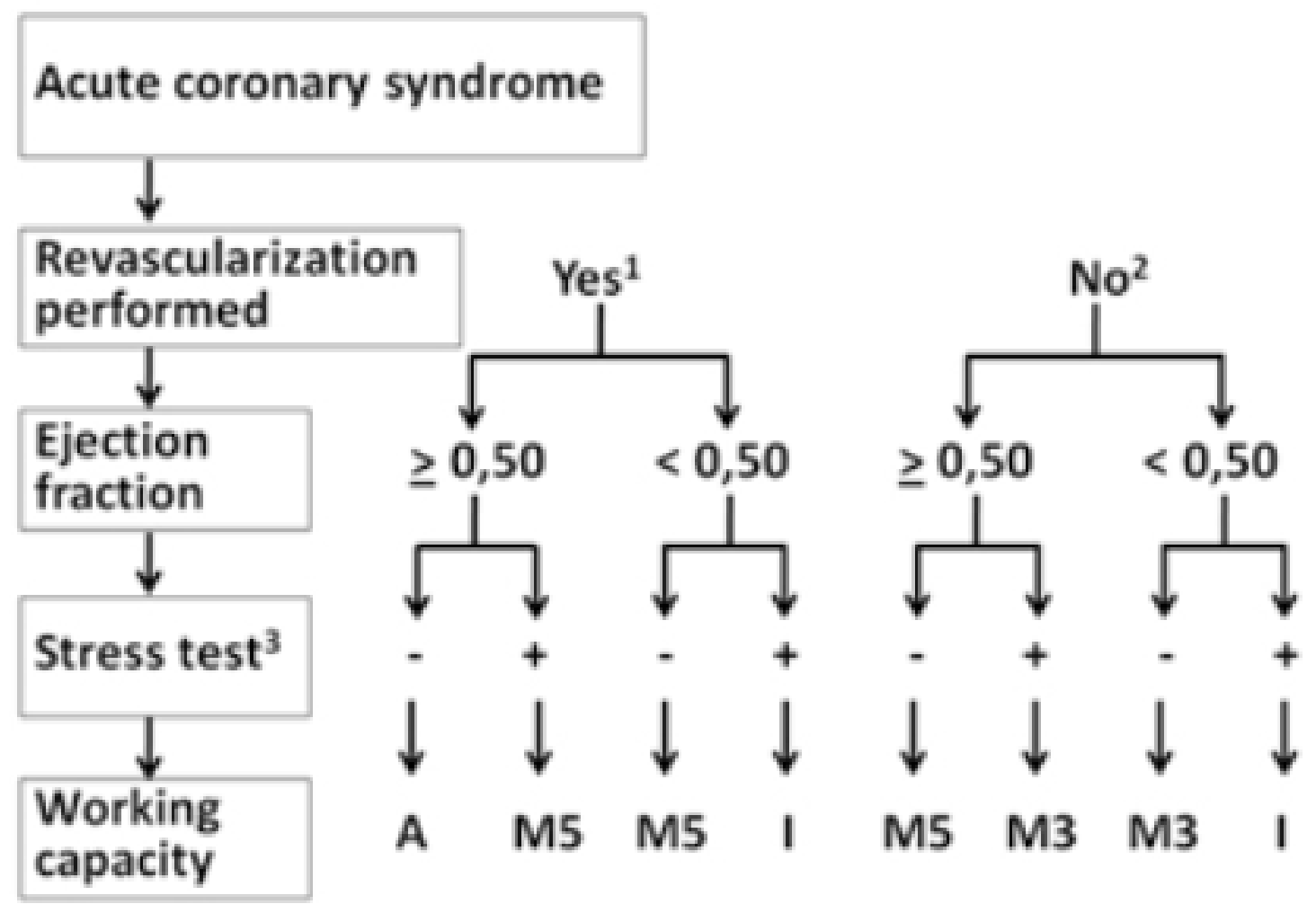

Figure 1. Return to Work Algorithm in acute coronary syndrome

Based on figure 1, revascularization performed by PCI or surgery, where echocardiography to asses ejection fraction. Symptom Limited Stress Test (SLST) results are negative if there are no clinical symptoms and EKG abnormality, and positive if there are clinical symptoms and abnormal ECG. Abnormal ECG is in the form of ST depression $>1 \mathrm{~mm}$ or ventricular arrhythmias at $>7$ METs. The symbol of " $A$ " is cleared for any type of work, "M5" can perform tasks < 5 METs, "M3" can perform < 3 METs, and "I" is not suitable for any type of work.

\section{Return to Work Programs}

Based on the WHO in the Expert Committee on
Rehabilitation of Patients with Cardiovascular Disease, the terms of employment for heart patients about works were not increase the physical burden, require specific abilities, and provide satisfaction, security and promotion.

Return to work may postpone in patients with functional capacity class III or IV for a few weeks and functional test should be performed to identify level of capacity. Based on the Seiller study, $56 \%$ of patients with New York Heart Association (NYHA) class I and II are prior to return to work. ${ }^{14}$ The relationship between the physiological classification of work capacity can be seen in table $4 .^{2}$ 
Table 4. Relationship between Energy Capacity and Cardiac Function Classification and Work

\begin{tabular}{|c|c|c|c|}
\hline $\begin{array}{l}\text { Work } \\
\text { Classification }\end{array}$ & $\begin{array}{l}\text { Cardiac } \\
\text { Function } \\
\text { Classification }\end{array}$ & Physiological Symptoms & METs \\
\hline Severe - very severe & Normal & Normal & $>6$ \\
\hline Moderate-severe & I & $\begin{array}{l}\text { Heart disease without physical activity restriction. } \\
\text { Ordinary activity does not cause symptoms }\end{array}$ & $>5$ \\
\hline Mild-moderate & II & $\begin{array}{l}\text { Heart disease with mild-moderate physical activity } \\
\text { restriction, severe activity cause symptoms }\end{array}$ & $3-4$ \\
\hline Sedentary-mild & III & $\begin{array}{l}\text { moderate heart disorder with moderate-severe } \\
\text { physical activity restriction, mild activity cause } \\
\text { symptoms }\end{array}$ & $2-3$ \\
\hline Sedentary & IV & $\begin{array}{l}\text { Heart disorders with persistent symptoms at work } \\
\text { or rest }\end{array}$ & $1-2$ \\
\hline
\end{tabular}

Source: Wenger NK and Hellerstein HK. Rehabilitation of the Coronary Patient. 3rd Edition. Churchill Livingstone, 1992

Class I is low risk or moderate occupational classification. There is no limit to walking, climbing, crawling, kneeling, standing, bending, bending, reaching. However, must be careful while running. Patients allowed to lift and carry a load of $25-50 \mathrm{lbs}(0.4536 \mathrm{~kg})$. Working environmental is not limited by temperature, humidity, dust, high places, night shift, and driving vehicle. It is recommended to change work every 8 hours. $^{2}$

Class II is a moderate risk or light work classification. There is no limit to crawling, kneeling, standing, bending, bending and reaching out. Patients are careful when walking, running, can climb stairs 2 steps three times in one hour and lift and carry a load of 20-25 lbs. Working environmental is not restricted except for outdoor activities, may not exceed usual activities and be careful of extreme temperatures. ${ }^{2}$

Class III is a high-risk patient or sedentary job classification. Patients can not; run, crawl and kneel. Patients allowed to go up 1 or 2 steps, lift or carry a maximum load of $10 \mathrm{lbs}$. Working environmental is limited by extreme temperature and the work shift should be in a rotation.

After a comprehensive evaluation such as assessment of functional capacity and risk stratification, it is important to determine suitability for work. There are 3 outputs patients to return to work, such as ${ }^{2}$; Return to work without a limitation, return to work with a limitation, and not able to return to work caused of physical limitation or no suitable work. 
Return to work on post-PCI ACS patients may need some adjustments such as: Job modification to reduce energy requirements by changing the environment, work designs, and task of jobs; Selective placement is move to another job that has less requirements by moving to another division in the same company; Individual capacity improvement by exercise training program, psychological and emotional support and/or medical procedure; and Resignation or retirement if the above is not possible. ${ }^{2}$

\section{Conclusion}

The prevalence and the mortality of CHD in Indonesia is increasing by the year. The early form of CHD is the ACS. Rehabilitation program on ACS is essential to improve physical health and quality of life, furthermore to reduce the social-economy burden. Rehabilitation on ACS consists of Initial and early mobilization, identification of the risk factors, and continuing cardiac rehabilitation program. There are three phase of cardiac rehabilitation program; phase I (inpatient) to reach functional capacity 3-4 METs for 5 days, phase II (outpatient) to reach functional capacity 6-8 METs for 4 to 8 weeks, and phase III (maintenance) to reach functional capacity more than 8 METs for 3-6 months. Evaluation of risk stratification is necessary to determine the intensity of exercise.

Return to work is the main role of cardiac rehabilitation on ACS. There are many factors affected return to work, i.e. medical condition, sociodemographic, psychosocial, and occupation $\&$ work factor. The works evaluation is needed in patients return to work, included work risk, work capacity, and work tolerance, as the guidance of rehabilitation program. There are four cardiac function classification, whereas class I and II are priority to return to work, while class III and IV may postpone after the functional test to find the proper work intensity.

\section{REFERENCES}

1. Moshe S, Levy D and Harefuah SH. Return to work with heart disease. $2007 ; 146(2)$ :1139, 165.

2. Wenger NK and Hellerstein HK. Rehabilitation of the Coronary Patient. International Journal of Cardiology. 1993; 38(1):106-107.

3. Dreyer RP and Dickson VV. Return to work after acute myocardial infarction. Circ Cardiovascular Qual Outcomes. 2018;11:e004806.

4. Amsterdam EA, Wenger NK, Brindis RG, et al. 2014 ACC/AHA guideline for the management of patients with non-STelevation acute coronary syndromes: a report of the American College of Cardiology/ American Heart Association Task Force on Practice Guidelines. Circulation. 2014;130:344-426.

5. Mozaffarian D, Benjamin EJ, et al. Executive Summary: Heart Disease and Stroke Statistics--2016 Update: A Report From the American Heart Association. Circulation. 2016;133:447-54.

6. Widimsky P, Zelizko, Jansky P, Tousek F, Holm F, Aschermann M. The incidence, treatment strategies and outcomes of acute coronarysyndromes in the"reperfusion network " of different hospital types in theCzech Republic: Results of the Czech evaluation of acute coronarysyndromes in hospitalized patients (CZECH) registry. International Journal of Cardiology. 2007; 
119:212-219.

7. Kementrian Kesehatan Republik Indonesia. Data Riset Kesehatan Dasar Indonesia 2013 (RISKESDAS). 2013.

8. PERKI. Pedoman Tatalaksana Sindrom Koroner Akut. PERKI. 2018;4.

9. American Association of cardiovascular and pulmonary Rehabilitation. Guidelines for Cardiac Rehabilitation and Secondary Prevention Programs. Human Kinetics; 2013.

10. Basuni DT, Putra LH. Rehabilitasi Kardiovaskuler. Perdosri. 2016.

11. Pescatello LS, American College of Sports Medicine. ACSM's guidelines for exercise testing and prescription. Philadelphia: Wolters Kluwer/Lippincott Williams \& Wilkins Health; 2014.

12. Piepoli MF. Secondary prevention through cardiac rehabilitation: physical activity counselling and exercise training: key components of the position paper from the Cardiac Rehabilitation Section of the European Association of Cardiovascular Prevention and Rehabilitation. European Heart Journal. 2010; 31(16): 1967-1974.

13. Thomas RJ, Goel K, Lennon RJ, et al. Squires. Impact of cardiac rehabilitation on mortality and cardiovascular events after percutaneous coronary intervention in the community. Circulation. 2011;123:2344-2352.
14. Dendale P, Berger J, Hansen D, et al. Cardiac rehabilitation reduces the rate of major adverse cardiac events after percutaneous coronary intervention. Eur J Cardiovasc Nurs. 2005;4(2):113-6.

15. Brede E, Ikram F, Howard $K$, et al. Measurement of Return to Work and Stay at Work Outcomes. In : Handbook of Return to Work, Handbooks in Health, Work, and Disability. Springer. 2016.

16. Fiabane E, Omodeo O, Argentero P, et al. Return to Work after an Acute Cardiac Event: the Role of Psychosocial Factors. Journal Prevention and Research. 2014 3(4): 137141.

17. Philippe Sellier. Returning to Work after Coronary Intervention In: Joep Perk PM, Helmut Gohlke, Catherine Monpère, Irene Hellemans, Hannah McGee, Philippe Sellier, and Hugo Saner, editor. Cardiovascular Prevention and Rehabilitation. Springer. 2007; 324.

18. Becker TJ. Functional Capacity Evaluations: The Work Physiology Component for Predicting Full-time Work. Directiom in Rehabilitation Coumeling. 8:177-185.

19. Reporting on coronary patients for return to work: an algorithm. An article from the e-journal of the ESC Council for Cardiology Practice. 2012; 10:20-23. 